\title{
DESJUDICIALIZAR VS. JUDICIALIZAR LA FAMILIA EN MÉXICO, SU IMPACTO EN EL DERECHO
}

\author{
Judicialize against not judicialize family in México, its impact on the law
}

Yolanda REYES ZÁRATE

\begin{abstract}
Sumario:
I. Introducción. II. Antecedentes de la familia. III. Naturaleza jurídica del Derecho Familiar. IV. La situación actual del Derecho Familiar en México. V. Judicialización frente a desjudicialización. VI. La gratuidad del Derecho Familiar. VII. El papel de las instituciones. VIII. La jurisprudencia en el Derecho Familiar. IX. Conclusiones. X. Fuentes.
\end{abstract}

Resumen: En el sistema jurídico mexicano, la familia es considerada como una institución y por ser una cuestión de orden público e interés social, al Estado y al Derecho, les interesa regularla; a fin de que ante los órganos jurisdiccionales se resuelvan las controversias que involucran a los miembros que la integran, el concepto de familia ha ido evolucionando, pues a medida que la sociedad cambia, este grupo social se ha venido conformando de una distinta manera que va más allá de una mera relación biológica entre personas que tienen un mismo origen, porque provienen unas de otras, extendiéndose.

Lo que trae como consecuencia también que el Derecho Familiar tenga otros componentes nuevos, de carácter sustantivo y también adjetivo, pues a su vez produce cambios a nivel Procesal, como rama especializada de Derecho de regular a la familia, existe discusión en torno a su autonomía, porque hay controversia sobre su propia naturaleza jurídica.

El punto en cuestión, es determinar en qué medida ha de ser regulada la familia por el Derecho, pues hay una postura de que debe judicializarse para resolverse ante los órganos jurisdiccionales las controversias que entre sus miembros se producen; pero existe otra perspectiva, relativa a que ya se tiene que desjudicializar, para que sean sus propios integrantes quienes resuelvan por sí mismos sus conflictos o en todo caso acudan ante otras instancias o vías no judiciales, como mecanismos alternos de solución de controversias, siendo dos visiones opuestas, se pretende encontrar una solución que beneficie a la familia.

Palabras clave: Derecho Familiar, juzgar, México.

Abstract: In the Mexican legal system, the family is regarded as an institution and be a matter of public order and social interest, the state and the law regulating it interests them; so that before the courts disputes involving members who compose are resolved, the concept of family has evolved, because as society changes, this social group has been forming in a different way

\footnotetext{
${ }^{1}$ Doctora en Derecho con Orientación en Derecho Procesal por la Universidad Autónoma de Nuevo León. Maestría en Derecho fiscal por la Universidad de Guanajuato y Maestría en Derecho Civil por la Universidad de La Salle Bajío. Labora en el Poder Judicial del Estado de Guanajuato por carrera judicial. Catedrática de posgrado en la Universidad de La Salle Bajío.
} 
that will beyond a mere biological relationship between people who have the same origin, because they come from each other, spreading.

Which results in the Family Law also have other new components, substantive and adjective, as in turn causes changes at a procedural level, as a specialized law regulating the family branch, there is discussion on autonomy because there is controversy over its legal nature.

The point at issue is to determine to what extent must be regulated by the Family Law, as there is a position that should judicializarse to resolve before the courts disputes occur among its members; but there is another perspective on that and you have to desjudicializar, to be its own members who solve their own conflicts or at least come to other bodies or judicial remedies as alternative mechanisms for dispute resolution, being two opposing views, is to find a solution that benefits the family.

Key words: Familiar Law, to judge, Mexico.

\section{INTRODUCCIÓN}

El presente artículo, versa sobre la situación actual que guarda el Derecho Familiar en México, desde dos ópticas totalmente opuestas y que son la desjudicialización y la judicialización de la familia; dado que ésta es una institución jurídica que no puede soslayarse, ha sido estudiada por diversas ciencias y en lo que al Derecho atañe, ocupa una posición especial, puesto que se habla del Derecho Familiar y del Derecho Procesal Familiar, como ramas autónomas e independientes, bajo esa postura de la especialización, separadas del Derecho Civil propiamente, al que se le atribuye cuestiones meramente patrimoniales.

De manera que el ámbito jurisdiccional cobra relevancia, porque los procedimientos civiles existentes se han tenido que actualizar, para ajustarse a las necesidades imperantes de la realidad social, al nuevo paradigma neoconstitucional de los Derechos Humanos y acorde a los Tratados Internacionales, efectuándose una evolución jurídica en cuanto a la forma de regular a la familia; primero, a manera de juicios especiales o sumarios, para que más ágilmente se resolvieran los conflictos relativos a la familia y recientemente, mediante la implementación de juicios orales, bajo la denominación de Sistema Oral Familiar (SOF), dedicado a conocer y resolver este tipo de juicios.

\section{ANTECEDENTES DE LA FAMILIA}

La palabra familia, proviene del latín famel, famulus, significa sirviente o esclavo, se refiere al siervo que no sólo recibe un sueldo por su trabajo, sino que vive bajo la dependencia de su señor, en cuanto a su habitación, vestido y alimentos; ya que la familia era sinónimo de patrimonio, pues incluía no solamente a los parientes, sino también a los sirvientes, de la casa del amo. ${ }^{2}$

La familia es un grupo de personas emparentadas entre sí que viven juntas; es un conjunto de ascendientes, descendientes, colaterales y afines que presentan una misma procedencia o

\footnotetext{
${ }^{2}$ Diccionario de latín, en: https://es.glosbe.com 
tienen un origen que comparten; son los hijos o descendencia; es un conjunto de personas que tienen alguna condición, opinión o tendencia común.

El concepto de familia ha sido estudiado desde la antigüedad por diversas áreas del conocimiento, siendo concebida como la primera célula de la sociedad o grupo primario dentro del cual se inicia el desarrollo de la persona humana; es producto de una época determinada que va dejando plasmada una imagen a través de la historia y ha cambiado desde su estructura hasta sus efectos legales, por lo que actualmente es regulada por el Derecho como una institución jurídica. Inclusive, los menores de edad han dejado de ser objeto del Derecho, para convertirse en sujetos del mismo, con fundamento en la Convención sobre los Derechos del Niño, de la que el Estado Mexicano es parte.

Desde una perspectiva biológica, a la familia se le ha venido catalogando dependiendo del tipo de miembros que la integran y la función que dentro de ella desempeñan; ${ }^{3}$ como una familia nuclear, cuando abarca padres e hijos que viven en común; a manera de familia extendida, incluyendo además de los padres e hijos, a los nietos también, viviendo en común; y, como una familia compuesta, derivada de la poligamia y poliandria, en atención a diversos factores que de hecho y de derecho ocurren, tales como los varios divorcios y nuevos matrimonios o relaciones de una persona que producen descendencia.

Así que desde una visión biológica, la familia puede ser ampliada, hasta la totalidad de las personas que comparten una misma carga genética, porque los une un lazo de sangre; este es un concepto elemental que trasciende al campo jurídico, en atención a que una familia o una simple pareja, son regulados por el Derecho, produciendo dicha institución de la familia, figuras jurídicas.

\section{NATURALEZA JURÍDICA DEL DERECHO FAMILIAR}

El Derecho Romano entendía por familia o domus, la reunión de personas colocadas bajo la autoridad de la manus de una sede única; hoy en día, el concepto de familia, tiene más bien una visión pragmática, porque le asigna esa característica al grupo de personas que viven o funcionan como tal, ya en el ámbito jurídico cabe precisar que la familia es considerada como una institución. ${ }^{4}$ Así que por ser una cuestión de orden público e interés social, el Estado y el Derecho se han ocupado de regular a la familia.

Se ha intentado encuadrar a la familia, para que sea materia de estudio como una rama del Derecho, denominada Derecho de Familia o Derecho Familiar, algunos la clasifican dentro del Derecho Privado, otros la colocan en el Derecho Público o para un tercer sector, como un Derecho Social; se le ha atribuido a Antonio Cicu (1879-1962), catedrático de la Universidad de Bolonia, Italia la idea de establecer al Derecho de Familia como una rama autónoma de Derecho, ya que en 1913 en una conferencia sostuvo tal postura de que al Derecho Fa-

3 BAQUEIRO ROJAS, Édgard y BUENROSTRO BÁEZ, Rosalía, Derecho de familia, $2^{\mathrm{a}}$ ed., edit. Oxford, México, 2009, pp. 3-6.

4 DE LA MATA PIZAÑA, Felipe y GARZÓn JIMÉNEZ, Roberto. Derecho Familiar, 4aed., edit. Porrúa, México, 2008, pp. 3-8. 
miliar se le podría asignar una posición independiente y distinta del Derecho Público y el Derecho Privado. ${ }^{5}$

Inclusive, se ha realizado la propuesta de federalizar al Derecho Familiar, como en su momento estuvo regulado en la época de Venustiano Carranza, en la Ley de Relaciones Familiares de $1917 ;^{6}$ es decir, que a través de una legislación única de carácter general y por tanto federal, para todas y cada una de las Entidades Federativas, exista un solo Código Civil y uno único de Procedimientos Civiles que regule a la familia, en lugar de que cada Estado, como hoy ocurre, tenga su propio Código Sustantivo Civil y su Legislación Adjetiva que la norme y varíe de un lugar a otro, también para evitar que sólo ciertas Entidades del país mexicano, cuenten con un Código Familiar separado e independiente.

Hidalgo, Michoacán, Morelos y San Luis Potosí, por citar algunos, son Estados que cuentan con un Código Familiar, independiente de su Código Civil $;{ }^{7}$ mientras que Guanajuato ${ }^{8}$ y Nuevo León, ${ }^{9}$ son Estados que no tienen un Código de Familia, pero han actualizado su legislación para que en el Sistema Oral Familiar, mediante un juicio de esa naturaleza, donde se atienda a los principios constitucionales de inmediación, continuidad, concentración, colaboración y abreviación, se resuelvan las controversias de carácter familiar, más rápido, eficiente y eficazmente, por un juez especializado en oralidad, continuando el tópico de la familia regulado dentro del Libro Primero del Código Civil, De las Personas.

La tendencia se dirige a apoyar la autonomía del Derecho Familiar, siendo cada vez más palpable la intención de regular y judicializar a la familia en todos sus aspectos que jurídicamente repercuten, pues se han establecido ciertos procedimientos especiales o especializados para resolver las controversias inherentes a la familia; al mismo tiempo que la mediación y la conciliación han cobrado especial relevancia, como Métodos Alternativos de Solución de Conflictos (MASC), por conducto de la llamada Justicia Alternativa. ${ }^{10}$.

La opinión generalizada, es determinar que el Derecho Familiar es Derecho Privado, pero de orden público e interés social; autores como Ernesto Gutiérrez y González, sostiene la hipótesis de que su correcta regulación, es el Derecho Civil para la Familia y manifiesta que en la institución jurídica denominada familia, no se puede hablar de obligaciones, sino de deberes: "el legislador nunca puede establecer en una Ley, una obligación, sino lo que establece es sólo deberes jurídicos". ${ }^{11}$

Nuevo León fue el primero en implementar juicios orales en la República Mexicana, en el Estado de Guanajuato, mediante Decreto publicado en el Periódico Oficial de fecha 27 de diciembre de 2011, se establecen los juicios orales en materia familiar, con entrada en vigor progresiva a partir del mes de agosto de 2012, primero en la ciudad de Guanajuato capital;

5 GUITRÓN FUENTEVILLA, Julián,“Derecho Familiar”, en Revista Jurídica UNAM, 1978, México, http:// www.juridicas.unam.mx/.2 agosto 2015.

6 Véase la Ley de Relaciones Familiares de 1917, en http://www.sitios.scjn.gob.mx/.31 de julio de 2015.

7 Consúltese el sitio de internet de cada uno de los Congresos del 31 Estados de la República y el del otrora Distrito Federal, ahora Ciudad de México, en el apartado de legislación correspondiente.

8 Congreso del Estado de Guanajuato, http://www.congresogto.gob.mx/. 25 de julio de 2015.

9 Congreso del Estado de Nuevo León, en: http://www.hcnl.gob.mx/.28 de julio de 2015.

${ }^{10}$ GORJÓN GÓMEZ, Francisco J. y STEELE GARZA, José G., Métodos alternativos de solución de conflictos, edit. Oxford, México, 2008, pp. 126-133.

${ }^{11}$ GUTIÉRREZ Y GONZÁLEZ, Ernesto, Derecho Civil para la Familia, 2a ed., edit. Porrúa, México, 20o9, p. 50 . 
luego en el año 2013 en las del corredor industrial y desde del $1^{\circ}$ de marzo de 2014 ya en todo el Estado de Guanajuato. ${ }^{12}$

\section{LA SITUACIÓN ACTUAL DEL DERECHO FAMILIAR EN MÉXICO}

El artículo $4^{\circ}$ de la Constitución Política de los Estados Unidos Mexicanos, establece en lo esencial: "El varón y la mujer son iguales ante la ley. Esta protegerá la organización y desarrollo de la familia. Toda persona tiene derecho a decidir de manera libre, responsable e informada sobre el número y el espaciamiento de sus hijos..."; dicho precepto de la Carta Magna, es la base del marco normativo que regula a la familia y a su vez, ya sea dentro de un Código Civil o en un Código Familiar propiamente, está legislada en cada una de las Entidades de la República Mexicana y también en el otrora Distrito Federal, ahora ciudad de México.

En las últimas décadas, en Latinoamérica se han venido realizando estudios de Derecho Comparado sobre la familia, ${ }^{13}$ para enfatizar la construcción de un derecho procesal familiar, separable del Derecho Procesal Civil, con una sistematización propia; aún y cuando se parte del ordenamiento total, como Teoría General del Proceso, actualmente no pasa desapercibido también, el hecho de que está presente el Derecho de Minoridad, no separable aún del Derecho de Familia.

$\mathrm{Al}$ respecto, la investigadora Matilde Coutiño Castro, ${ }^{14}$ reseña que hay innumerables trabajos sobre el Derecho y las Ciencias Sociales en torno a los derechos de los menores o derecho de los niños, considerados como sujetos de derecho, dentro de una rama autónoma y distinta del Derecho Civil y del Derecho Familiar; este tipo de autores modernos, reconocen la plena independencia y autonomía al Derecho que los regula.

El Derecho para los menores de edad, se ha venido denominando como Derecho de la Minoridad, Derecho de Minoridad, Derecho de Menores de Edad o Derecho para Menores de Edad, dice Joel Francisco Jiménez García ${ }^{15}$ que tiene por objeto la protección integral del ser humano, desde el momento de su concepción hasta que alcanza la plena capacidad de obrar, que inicia con la mayoría de edad.

El Derecho Internacional marca la pauta para la reestructuración del Derecho Interno, en atención a los tratados y convenios en materia internacional; en un sentido estricto se habla del interés superior del niño y de la protección de los menores de edad ya nacidos, abarcando

\footnotetext{
${ }^{12}$ Periódico Oficial del Gobierno del Estado de Guanajuato, visible en: http://periodico.guanajuato.gob.mx/ ver publicación del 27 de diciembre de 2011.15 de julio de 2015.

${ }^{13}$ Sobre el Derecho de Minoridad, en México no existe gran cantidad de doctrina; a diferencia de países de habla hispana como Argentina o Perú, en donde sí se le reconoce como rama autónoma, con doctrina sólida desde principios de 1990 .

14 COUTIÑO, Castro Matilde, "El Derecho de los Menores: Una Perspectiva Nacional e Internacional”, en Biblioteca Jurídica Virtual del Instituto de Investigaciones Jurídicas de la UNAM, en http://www.juridicas. unam.mx/.13 de julio de 2015.

15 JIMÉNEZ GARCÍA, Joel Francisco, “Derecho de los Niños”, en Revista del Instituto de Investigaciones Jurídicas de la UNAM, México, 200o, pp. 4-5.
} 
a los niños, infantes y adolescentes, hasta antes de cumplir su mayoría de edad; no obstante, para María Montserrat Pérez Contreras, ${ }^{16}$ no comprende a los concebidos aún no nacidos.

Cabe mencionar que en algunas Entidades de la nación mexicana, ya se encuentra contemplada la obligación de dar alimentos al concebido, como el Código Civil para el Estado de Guanajuato que en su artículo 357 así lo establece. ${ }^{17}$

El Derecho Familiar se ha vuelto cada vez más flexible, evitando el rigorismo y formalismo que impidan el acceso a la justicia; por tanto, los principios de oficiosidad y suplencia son los imperantes, el juez como director del proceso, trae pruebas al juicio y de oficio da impulso procesal, siempre en aras del interés superior de la niñez.

\section{JUDICIALIZACIÓN FRENTE A DESJUDICIALIZACIÓN}

Para Diego Benavides Santos, ${ }^{18}$ existen principios especiales para un diseño ideal de procedimiento específico, a la par de los principios procesales derivados del debido proceso, pero ya adaptados al Derecho Procesal de Familia; este autor precisa, que los diseños de los principios procesales específicos para una rama del Derecho, deben ser adecuados a cada área, siendo dualistas, porque se colocan en los extremos entre la publicidad-privacidad, oralidad-escritura, dispositivo-inquisitivo e impulso de parte-impulso oficial entre otros.

Dentro de estos principios, están la desjudicialización, la descontención, el abordaje integral, la solución efectiva con celeridad y la búsqueda de la equidad y del equilibrio procesal; implica llevar a cabo un estudio interdisciplinario que abarca la especialización de los órganos jurisdiccionales, en torno a todos sus participantes, internos y externos, los abogados de las partes y los resolutores de este tipo de asuntos, porque implica contar con recursos económicos y humanos, debidamente capacitados, actualizados y especialistas en la materia.

Con la mención de que algunos tipos de sentencias, respecto a menores de edad no tienen el distingo de cosa juzgada propiamente, en el sentido tradicional; por los cambios continuos de situación jurídica que pueden originarse, tales como los juicios relativos a alimentos, para adecuarse la pensión a la necesidad del acreedor y a la posibilidad de su deudor; son ciertas peculiaridades que se presentan en los juicios relativos a la familia y a los menores de edad.

Ricardo C. Pérez Manrique [19], señala que la doctrina ha elaborado diversas clasificaciones, en torno a la forma de participación de los menores de edad como miembros integrantes de una familia, desde la decisión exclusiva a cargo del niño, hasta la omisión de su participación; la última opción indicada, seria violatoria de la Convención de los Derechos el Niño y la primera va más allá de lo establecido, porque no se le puede entregar a un niño

${ }^{16}$ PÉREZ CONTRERAS, María Montserrat, "Comentarios a la Ley para la Protección de los Derechos de Niñas, Niños y Adolescentes”, en Revista de la Facultad de Derecho de la Universidad Autónoma de México, número 235, tomo LI, México, 2001, p. 275.

17 “ARTÍCULO 357. Los padres están obligados a dar alimentos a sus hijos desde el momento en que son concebidos. A falta o por imposibilidad de los padres, la obligación recae en los demás ascendientes por ambas líneas que estuvieren más próximas en grado.” (Artículo Reformado. P.O. 17 de mayo de 2013).

${ }^{18}$ BENAVIDES SANTOS, Diego, “Tendencias del Proceso Familiar en América Latina”, en Revista INDRET para el Análisis del Derecho, 2006, año 1, número 321, Barcelona España, http://www.indret.com.18 de agosto de 2015.

19 PÉREZ MANRIQUE Ricardo C., "Participación Judicial de los Niños, Niñas y Adolescentes”, en Revista Justicia y Derechos del Niño, Número 8, Sección Primera, Artículos para el Debate, $1^{\mathrm{a}}$ ed., Santiago de Chile: UNICEF, año 2006, pp. 219-248, http://www.unicef.org/argentina/spanish/JusticiayDerechos.17 de agosto de 2015. 
la totalidad de sus decisiones sobre sí, pues se estarían desconociendo las obligaciones de su familia, la sociedad y del Estado, respecto de los derechos de los niños.

$\mathrm{Al}$ revisar estas posturas, se advierte que se cae en los extremos, porque no hay formas definidas en la Ley que indiquen cómo escuchar adecuadamente a un menor de edad y hasta ahora solamente se ha determinado que debe hacerse en función de su edad y madurez, dependerá entonces en cada caso concreto de una facultad discrecional del juez oírlos cuando lo estime necesario; en la práctica, la diligencia de escucha del menor, se hace presente, dependiendo del desarrollo que el infante, niño o adolescente presente y siempre debe ser con apoyo de un profesional del área de trabajo social o psicología que se encuentre presente.

Ante ese contexto, es cuando surge la pregunta: ¿desjudicializar o seguir judicializando cada vez más a la familia?, son las dos posturas extremas que en la actualidad se producen, ya que el Estado y el Derecho en una especie de responsabilidad compartida, con los ascendientes o cabezas de familia, se comprometen a regularla, permitiendo los últimos que los órganos impartidores de justicia sean quienes resuelvan sus problemas que en torno a la familia se presentan; es mejor continuar haciéndolo, porque si no fuese normada como institución jurídica sería muy utópico pensar que por sí mismos, sin la intervención de un juez, podrían solucionar sus conflictos, así que tienen que acudir a una instancia judicial, para hacerlo o incluso pueden llegar a un convenio judicial durante el proceso o previo a iniciar un litigio acudir ante la llamada Justicia Alternativa.

Osvaldo M. Álvarez Torres ${ }^{20}$ indica que no se trata de buscar la desjudicialización por la desjudicalización; por ejemplo, el utilitarismo de desjudicializar asuntos, puede ir desde la tramitación administrativa de un asunto de familia para resolver un conflicto o llegar a políticas contravencionales o notariales, para "aliviar” la radicación judicial que en estadísticas se refleja con aumento continuo de juicios sobre divorcio, pérdida de patria potestad y también contiendas sobre pago de pensión alimenticia, son controversias que han incrementado el número de juicios que se tramitan.

Este autor, añade que los asuntos familiares o sobre menores de edad, cuyo conocimiento y resolución pretenden ser llevados a vías no judiciales, específicamente a una sede notarial o administrativa, -adopción, tutela, declaración de incapacidad, utilidad y necesidad-, no constituyen la mayoría de la radicación de los Tribunales; por ello, ni provecho o ventaja resultaría quitarlos del conocimiento de los jueces, pues se correría el riesgo de someter a convenciones avaladas por un funcionario público unipersonal asuntos de gran trascendencia que solamente un juez está en aptitud de decidir.

Con la denominada Justicia Alternativa, en concordancia con el contenido del artículo 17 Constitucional, se pretende la solución de conflictos antes de iniciar el juicio o durante el mismo, para concluirlo cuanto antes; con la única limitante de que en materia familiar, no es posible disponer de ciertas cuestiones de orden público o interés social, sobre las que no se puede convenir y en los puntos que sí son susceptibles de acuerdo, pero siempre que no se afecten derechos de terceros, porque los alimentos o la patria potestad son irrenunciables; en materia civil y en materia penal, cuando el conflicto es generado por violencia intrafamiliar, no cabe conciliación o mediación y hay derechos personalísimos no transferibles y que por ende, no son susceptibles de llegar convenio.

En resumen, cuando el contenido es patrimonial, se puede realizar mediación o conciliación, pero desde el momento en que se involucran instituciones o derechos irrenunciables,

${ }^{20}$ ÁLVAREZ TORRES, Osvaldo M. ¿Por qué la desjudicialización de la justicia de familia?, en Revista Contribuciones a las Ciencias Sociales, marzo 2011, www.eumed.net/.20 de agosto de 2015. 
como la patria potestad o los alimentos, no es dable hacerlo, a menos que sea sobre la cuestión pecuniaria que los involucra; sin que la judicialización llegue tampoco al extremo en el que el juez tenga que decidir cualquier situación, pues las partes deben proponer y participar para lograr un acuerdo, no puede el resolutor allegarse todas las pruebas, pues se rompería el equilibrio procesal entre las partes.

Se busca encontrar un punto medio, en donde el juez desempeñe su función dinámica, con oficiosidad y suplencia, pero con límites, porque ningún derecho puede ser total, ya que vulnera el de los demás; y, las instituciones deben desempeñar su papel que les corresponde, siguiendo un modelo integral, el beneficio es para los menores de edad y sobre todo respetando las formalidades esenciales del procedimiento se produce certeza.

\section{LA GRATUIDAD DEL DERECHO FAMILIAR}

Mediante las reformas a la Constitución Política de los Estados Unidos Mexicanos, publicadas en el Diario Oficial de la Federación del 10 de junio de $2011,{ }^{21}$ se modifica sustancialmente la Carta Magna, destacándose la denominación del Capítulo Primero del Título Primero "De los Derechos Humanos y sus Garantías"; para la Suprema Corte de Justicia de la Nación, es una de las reformas más importantes, porque impacta directamente en la administración de justicia federal, ven robustecido el juicio de amparo al ampliar su procedencia respecto de cualquier norma general; se prevé procede por violaciones a derechos humanos plasmados en los tratados internacionales de los que el Estado mexicano es parte.

Se introducen figuras como los intereses legítimos individual y colectivo; se adoptan nuevos conceptos en torno a la violación de derechos por omisión de autoridades; la declaratoria general de inconstitucionalidad con alcances a determinar en la Ley reglamentaria; la creación de los Plenos de Circuito; una nueva forma de integrar jurisprudencia "por sustitución"; se reconoce la progresividad de los derechos humanos, mediante el principio pro persona como rector de interpretación y aplicación de normas jurídicas; y amplía los derechos de algunas cláusulas constitucionales, como de los migrantes o a la suspensión de garantías. ${ }^{22}$

Estas reformas contienen la obligación expresa de observar los tratados internacionales firmados por el Estado Mexicano que tienden a mejorar las condiciones de vida de la sociedad y el desarrollo de cada persona en lo individual, se reconocen derechos humanos y en los que el Estado mexicano es parte; es por lo que se ha estimado indispensable hacer del conocimiento público un listado enunciativo, no limitativo, de los instrumentos internacionales de esa naturaleza, clasificados por la materia en que inciden.

Para Sergio García Ramírez, ${ }^{23}$ si se habla de protección o tutela de los derechos humanos en general y en particular, hay que aludir primero a instrumentos nacionales, porque la primer defensa reside en los Estados, obligados por sus propias normas a reconocer y garantizar, los derechos primordiales de los sujetos que se encuentran bajo su jurisdicción; por la reforma indicada, una garantía es una herramienta o instrumento para proteger los derechos humanos, con base en los principios de universalidad, interdependencia, indivisibilidad y

\footnotetext{
${ }^{21}$ Reformas a la Constitución Política de los Estados Unidos Mexicanos, en http://www.dof.gob.mx/.2 de agosto de 2015.

${ }^{22}$ Consúltese el Diario Oficial de la Federación del 6 de junio de 2011, en: http://dof.gob.mx; así como el análisis de la reforma hecho por la Corte mexicana. Disponible en: http://www2.scjn.gob.mx/red/constitucion. 12 de agosto de 2015.

${ }^{23}$ GARCÍA RAMÍREZ, Sergio, Derechos Humanos para los Menores de Edad. Perspectiva de la Jurisdicción Interamericana, $1^{\mathrm{a}}$ ed. UNAM, México, 2010, p. 31.
} 
progresividad, la interpretación conforme y el principio pro persona orientados por la igualdad y la no discriminación; debiendo comprender la igualdad los aspectos, formal, material y estructural en todos sectores.

Al tenor de estas reformas, todas las autoridades en sus ámbitos de competencia tienen la obligación de promover, respetar, proteger y garantizar los derechos humanos, de conformidad con el principio de tutela judicial contenido en el artículo 17 de la Constitución Federal; ${ }^{24}$ debido a que los gobernados tienen derecho a una justicia apegada a las exigencias formales que la propia Carta Magna establece en materia jurisdiccional, partiendo siempre del artículo $1^{\circ}$ que abarca derechos humanos y garantías, relacionado con el $4{ }^{\circ}$ Constitucional que regula a la familia.

Entonces, en cuanto hace a la función jurisdiccional, debe impartirse justicia de manera pronta y expedita, imparcial y completa, con base en el respeto a los derechos humanos y con perspectiva de igualdad de género; aspectos entre los cuales, la familia es una institución de orden público e interés social que debe ser regulada y protegerse.

Es el caso que el M.P. ${ }^{25}$ y el D.I.F. ${ }^{26}$ son dos de las instituciones que cobran mayor relevancia en los juicios relativos a menores de edad y en general a la familia; además del papel importante del defensor de oficio denominado Representante Gratuito en materia civil, que en pocos Estados ha cobrado vida, pues generalmente se da en materia penal, pero civilmente ha surgido con gran demanda de sus servicios, y depende de la Secretaría de Gobierno, es decir, del Gobierno del Estado. ${ }^{27}$

En el presente estudio, se propone que solamente proporcionen sus servicios en asuntos de carácter familiar, para que cualquier persona con un problema de este tipo, sea asesorado en forma gratuita.

\section{EL PAPEL DE LAS INSTITUCIONES}

Los derechos y libertades de los menores de edad, deben estar debidamente garantizados por el Estado, quien también les tiene que imponer deberes, siendo el principal el de respeto a los demás y a la propiedad ajena; al efecto, tiene que contarse con instituciones adecuadas para

\footnotetext{
${ }^{24}$ Consúltese la Convención Americana sobre Derechos Humanos, la reforma constitucional y el Diario Oficial de la Federación de fecha 29 de julio de 2010, sobresale el cambio de denominación al capítulo primero Constitucional, conocido como garantías individuales artículos del $1^{\circ}$ al 29, que ahora se titula "De los Derechos Humanos y sus Garantías", por reforma publicada esta última el 10 de junio de 2011. Disponible en http://www.diputados.gob.mx.6 de agosto de 2015.

${ }^{25}$ En materia Federal, Estatal y en la Ciudad de México, el Ministerio Público está adscrito al Poder Ejecutivo y con las reformas en materia constitucional de 2008, con la implementación del sistema penal acusatorio, es palpable la transformación; sin embargo, en materia civil el Ministerio Público no ha tenido el desarrollo que amerita, para que se apoye de manera integral a la familia.

${ }^{26}$ El Desarrollo Integral de la Familia (DIF), en cada Estado de la República Mexicana cuenta con su DIF estatal posicionado en la capital de cada Entidad y cada municipio tiene su propio DIF municipal.

${ }^{27}$ En México sólo existían defensores de oficio en materia penal, pero poco a poco se ha logrado implementar defensores de oficio en otras áreas, como el derecho civil, estos dependen del Poder Ejecutivo; según las estadísticas son insuficientes para atender las demandas de la ciudadanía en general, se procura que atiendan asuntos previo estudio socioeconómico a personas de escasos recursos.
} 
poder lograrlo, siendo a quienes les corresponde realizar ese tipo de actividades, funcionando como un sistema de atención integral.

Mario Jesús Aguilar Camacho, ${ }^{28}$ basándose en la doctrina de Hauriou, analiza el concepto de institución, considerándola como el lugar de la acción social, la organización relacionada con el organismo; expresa, que la sociedad es como un cuerpo dotado de órganos y lo que ya está dado como poder de realización, es aquello que tiene una forma social determinada y está legitimado por la prolongación de su existencia.

Desde la firma de la Convención de los Derechos del Niño en 1989, se han organizado dos cumbres internacionales a favor de la Infancia, en 1991 y 2002, donde se han firmado compromisos para mejorar las condiciones de vida de los niños por parte de los gobiernos; ${ }^{29}$ lo que denota la participación cada vez más activa de Gobiernos y Estados y que las instituciones antes dichas, deben estar presentes como constantes, fungiendo mediante la realización efectiva de su labor encomendada, con una participación transversal; su papel activo es de gran importancia, para que se refleje la cabal tutela de los miembros de la familia.

\section{LA JURISPRUDENCIA EN EL DERECHO FAMILIAR}

En el artículo 14 de la Constitución Política de los Estados Unidos Mexicanos, ${ }^{30}$ último párrafo, se establece que: "En los juicios del orden civil, la sentencia definitiva deberá ser conforme a la letra o a la interpretación jurídica de la ley y a falta de ésta se fundará en los principios generales del derecho."; por disposición de la Carta Magna, los juicios civiles tienen que resolverse conforme al texto legal, aunque en la práctica, la jurisprudencia suple la Ley e incluso va más allá de ésta.

Por regla general, las Leyes Sustantivas Civiles de los Estados de la República Mexicana, contienen un capítulo inicial de disposiciones preliminares, en las que se contempla que el silencio, la obscuridad o la insuficiencia de la ley no autoriza a los jueces y tribunales para dejar de resolver una controversia judicial; lo cual obedece a que en el orden civil, cuando un conflicto no se puede resolver ni por el texto, ni por la interpretación jurídica de la ley, se tiene que decidir según principios generales de Derecho y tomando en consideración las circunstancias particulares del caso concreto y hoy en día no puede olvidarse el nuevo paradigma de los derechos humanos.

La doctrina puede ser argumento de autoridad, un elemento de análisis y de apoyo, ${ }^{31}$ cuando se está ante un conflicto de derechos, si falta ley expresa aplicable la controversia, se decide a favor de quien trate de evitarse perjuicios y no a favor del que pretenda obtener un

\footnotetext{
${ }^{28}$ AGUILAR CAMACHO, Mario Jesús, "Política y Derecho. Estudios para la Construcción de la Diversidad Democrática”, en Enciclopedia y Biblioteca Virtual de las Ciencias Sociales, Económica y Jurídicas, 2011, en http://www.eumed/. 26 de agosto 2015.

${ }^{29}$ El Fondo Internacional de las Naciones Unidas para la Infancia (UNICEF), respecto a los avances para mejorar las condiciones de vida de niños y adolescentes, presenta estadísticas, reportes e informes, de manera general a nivel mundial y en forma individual por cada país, en: http://www.unicef.org/.27 de agosto 2015.

${ }^{30}$ La Constitución Política de los Estados Unidos Mexicanos en vigor, data de 1917, contiene un sinnúmero de reformas y en cuanto al artículo 14 constitucional, destaca la publicada en el Diario Oficial de la Federación del 10 de junio de 2011 y la reforma a la Carta Magna es la publicada en dicho medio de difusión del 9 de febrero de 2012. Consúltese la página de Internet de la Suprema Corte de Justicia de la Nación, en el rubro relativo a recursos jurídicos, en relación con la Leyes Federales, Estatales y de la Ciudad de México, con cronología de reformas, en: http://www2.scjn.gob.mx/leyes/.19 de agosto 2015.

${ }^{31}$ Suprema Corte de Justicia de la Nación, Introducción a la Retórica y la Argumentación, 6a. ed. Suprema Corte de Justicia de la Nación, México, 2010, p. 482 y ss.
} 
lucro; cuando hay conflicto entre derechos iguales o de la misma especie, se debe decidir observando igualdad posible entre los interesados, esto refleja equilibrio procesal; de acuerdo con lo indicado, por disposición constitucional y legal, en materia civil una controversia se resuelve con base en la Ley y a falta de norma escrita, se hace uso de criterios de jurisprudencia o tesis aisladas, por ser fuente formal de derecho.

La palabra jurisprudencia proviene del latín iurisprudentia, iae, compuesta de las raíces ius, iuris y prudentia, iae; ${ }^{32}$ fue definida por los romanos como "arte de lo bueno y lo equitativo"; ${ }^{33}$ en el Manual del Juicio de Amparo de la Corte Mexicana, con propósitos docentes, proporciona un concepto de lo que es la jurisprudencia, como el conjunto de reglas o normas con los que la autoridad jurisdiccional cuenta con atribuciones al respecto, deriva de la interpretación de determinadas prevenciones del derecho positivo, que precisan el contenido que debe atribuirse y el alcance que debe darse a éstas y que al ser reiteradas cierto número de veces en sentido uniforme, no contrariado, son obligatorias para quien deba decidir casos concretos regidos por aquellas prevenciones. ${ }^{34}$

La sistematización y catalogación de la jurisprudencia se forma por épocas, son períodos que reflejan cambios paradigmáticos en la manera de conformarla, por la forma como se registran los criterios que constituyen la creación del Derecho a través de la actividad jurisdiccional; la mayoría de estos, se deben a reformas constitucionales y acontecimientos de gran relevancia histórica que impactan en el sistema jurídico nacional y se encuentran publicados en el Semanario Judicial de la Federación y su Gaceta. ${ }^{35}$

El año 2011 es histórico para el ámbito jurídico en México, debido a las recientes modificaciones a la Constitución; a partir de la reforma en materia de juicio de amparo, el Tribunal Pleno, con fecha 29 de agosto de 2011 emitió el acuerdo por el que se decreta el inicio de la décima época del Semanario Judicial de la Federación, con comienzo a partir del 4 de octubre del 2011 y cuyo acuerdo, se funda en la obligación de ajustar el trabajo sustantivo de las personas encargadas de la impartición de justicia a los requerimientos de la nueva realidad constitucional.

Hoy, en México, la totalidad de los intérpretes constitucionales tienen la obligación de realizar el llamado control de convencionalidad de cara al marco normativo de origen internacional en derechos humanos; los años por venir serán años de construcción y requerirán de la creatividad, eficiencia, voluntad y estricto cumplimiento de las reformas constitucionales por parte del Poder Judicial de la Federación y relevante es la entrada en vigor de la Nueva Ley de Amparo el 3 de abril de 2013. ${ }^{36}$

La jurisprudencia, se equipara a la Ley, porque aunque no es formalmente norma jurídica, materialmente tiene los atributos esenciales de una y son: la generalidad, la abstracción y la

${ }^{32}$ COUTURE, Eduardo J., Vocabulario Jurídico, con Especial Referencia al Derecho Procesal Vigente Uruguayo, edit. Depalma, Argentina, 1988, p. 372.

${ }^{33}$ HUBER OLEA, Francisco José, Diccionario de Derecho Romano comparado con Derecho Mexicano, edit. Porrúa, México, 200o, p. 296.

34 Suprema Corte de Justicia de la Nación, Manual del Juicio de Amparo, 2a ed., edit. Themis, México 1997, p. 175 .

35 El entonces presidente de México, primer mandatario durante varios períodos comprendidos de 1857 a 1872 , Benito Pablo Juárez García, mandó promulgar un decreto mediante el cual, determinó crear un periódico denominado Semanario Judicial de la Federación, cuyas publicaciones se han dividido en varios períodos, antes y después de la Constitución Política de los Estados Unidos Mexicanos de 1917, que es la vigente en este país, estando en vigor desde el 4 de febrero de 1995 la novena época, pero ahora, a partir de octubre de 2011 ha comenzado la décima época.

${ }^{36}$ Consúltese el sitio de internet de la Suprema Corte de Justicia de la Nación, en: http://www.scjn.gob.mx 
imperatividad, porque la jurisprudencia es obligatoria en términos de lo dispuesto por el artículo 94 de la Constitución Federal, en relación con el 217 de la Ley de Amparo que regula la obligatoriedad de la jurisprudencia, porque la ley fija los términos en que es obligatoria, la establecida por los tribunales del Poder Judicial de la Federación sobre interpretación de la Constitución, Leyes, Reglamentos y Tratados celebrados por el estado mexicano, así como los requisitos para su interrupción y modificación, indicados por el Manual de la Corte. ${ }^{37}$

La jurisprudencia es un producto social, que constituye una fuente formal del Derecho, no conforma legislación, sino que le sigue a ella, puesto que fija en la mayoría de los casos el contenido de una Ley y excepcionalmente la integra; ${ }^{38}$ siempre, la integración debe ser conforme a la Ley, porque no puede estar por encima de ella. La integración de la Ley se encuentra limitada por la norma constitucional, mientras que la jurisprudencia, en cuanto a su contenido, forma de creación y aplicación, también se encuentra restringida por la propia Ley.

El papel de la jurisprudencia es vital mencionarlo, porque ha venido a realizar la función de la ley, yendo más allá de su cometido de ser fuente formal del derecho; más que interpretación, ha permitido que tratándose de asuntos familiares, sean resueltos, acorde a la jurisprudencia; ante la falta de ley actual y actualizada.

Para Martha Chávez Padrón, ${ }^{39}$ el derecho es un todo armónico, no puede haber lagunas jurídicas, sino solamente lagunas legales, son vacíos normativos que se ha venido llenando con la jurisprudencia y reflejan la historia de este país, citando a Benito Juárez como jurista conocedor de la jurisprudencia; dice que es el punto del sistema de derecho escrito constitucional-social que se aproxima al sistema consuetudinario anglosajón, por ser una importante fuente, debido a que en aquel país, los jueces fundamentan sus sentencias en los hechos y las pruebas, pero también en precedentes.

Entonces, existe la obligación constitucional y legal, para las autoridades de acatar la jurisprudencia sostenida por la Suprema Corte de Justicia de la Nación y los Tribunales Colegiados que la forman, estando en aptitud de citarla de oficio; sin que proceda introducir en una resolución, doctrina o principios ajenos al litigio, dado que la jurisprudencia sostenida por el Poder Judicial Federal, no constituye una doctrina o una norma legal nueva o especial, sino que únicamente se constriñe a interpretar la norma existente, al emanar del análisis reiterado de disposiciones legales en función de casos concretos sometidos a su consideración y conforme a su competencia. Este es el alcance de la jurisprudencia y su limitación, es mera interpretación de la ley y no puede ir más allá de esta, tal como lo define la tesis de jurisprudencia de rubro: "JURISPRUDENCIA, CITA DE OFICIO DE LA, POR LA AUTORIDAD DEL ORDEN COMÚN".40

Para cumplir lo establecido por el artículo tercero del Acuerdo General número 12/2011, de fecha 10 de octubre de 2011, emitido por el Pleno de la Suprema Corte de Justicia de la Nación, a partir de entonces, la versión digital del Semanario Judicial de la Federación y su

\footnotetext{
${ }^{37}$ Suprema Corte de Justicia de la Nación, Manual del Juicio de Amparo, 2a ed., edit. Themis, México 1997, p. 175 y siguientes.

${ }^{38}$ Consúltense las diferencias entre la ley y la jurisprudencia, en http://biblio.juridicas.unam.mx.10 de agosto 2015.

39 CHÁVEZ PADRÓN, Martha, "El Proceso de Integración Jurisprudencial en el Sistema Jurídico Mexicano", en Revista del Instituto de Investigaciones Jurídicas de la UNAM, http://www.juridicas.unam.mx.12 de agosto 2015 .

${ }^{40}$ Tesis de jurisprudencia VI.20.J/188, Semanario Judicial de la Federación y su Gaceta, Tribunales Colegiados de Circuito, Novena Época, tomo XII, agosto de 2000, p. 1065, registro Ius 191453.
} 
Gaceta se publica en este portal de internet de la Corte, dentro de los primeros cinco días de cada mes; ${ }^{41}$ disponible vía Internet o en disco compacto.

Empero, la propia Corte y los Tribunales Colegiados, han reconocido que al sentar jurisprudencia, no solamente interpretan la Ley y estudian los aspectos que el legislador no precisó, sino que integran a la norma los alcances no incluidos, aunque la integración de la jurisprudencia no constituye una norma general como si lo es la Ley, a pesar de que en ocasiones llena las lagunas que ésta presenta, crea casos excepcionales de normas individualizadas, de acuerdo con los principios generales del derecho, previstos en el artículo 14 de la Constitución Política de los Estados Unidos Mexicanos.

Carlos Hugo Tondopó Hernández ${ }^{42}$ explica que se produce una necesidad de aplicar la jurisprudencia de manera retroactiva, de integrar la norma y fijar los alcances que tiene y esto es más común que se produzca en los asuntos familiares; para lograrlo, tiene que ser estudiada desde su origen, publicación y vigencia, acotando que no sólo le incumbe al Poder Judicial, sino a los demás tribunales que no son jurisdiccionales, porque su aplicación es obligatoria y ha de integrarse principalmente por reiteración o por contradicción de tesis, así mismo por las acciones de inconstitucionalidad, pues según este autor, esas son las tres formas reconocidas para que sea obligatoria, ya que las tesis aisladas son solamente mero apoyo para interpretar, pudiendo o no invocarse.

El mencionado autor concluye que el conocimiento de la jurisprudencia no es una prerrogativa, sino que es necesario y resulta obligatorio, para aquellos que trabajan en la impartición de justicia; porque su desconocimiento, atenta contra la propia justicia y dignidad humana; así que el tema de la jurisprudencia, desborda su importancia, que radica en su uso como herramienta indispensable, sin la cual no es posible lograr una correcta interpretación de la ley; puesto que se complementan entre sí y a medida que cambian los criterios, hacen que la Ley evolucione y tenga que modificarse, en aras de actualizarse, para adaptarse a la realidad social que supera le Ley y por eso coincido con la opinión de que la jurisprudencia le sigue a la Ley y en ocasiones hace que la legislación se actualice.

La palabra jurisprudencia se resume en interpretación de la Ley y por último, se tendrá que resolver con base en los principios generales de derecho; cobrando gran importancia que en lo relativo a asuntos que tienen que ver con menores de edad, se ha de resolver con base en principios, como el "interés superior del niño" y de acuerdo a la jurisprudencia o con la decisión de las sentencias en justicia, lo que también revela la desactualización de la ley, en este tipo de asuntos, pues requiere de reformas acordes a la realidad social actual.

\section{CONCLUSIONES}

Primera: La familia actualmente es considerada una institución de orden público e interés social que por tanto, no puede soslayarse; así que al Estado le interesa siga siendo regulada por el Derecho y que los conflictos que entre sus miembros se presentan, se resuelvan por

\footnotetext{
${ }^{41}$ Semanario Judicial de la Federación y su Gaceta, en http://www.scjn.gob.mx

42 TONDOPÓ HERNÁNDEZ, Carlos Hugo, "La Jurisprudencia en el Sistema Jurídico Mexicano. Necesidad de Aplicación Retroactiva y ampliación en su Alcance”, en Instituto de Investigaciones Jurídicas UNAM, http://www.juridicas.unam.mx.16 de agosto 2015.
} 
órganos jurisdiccionales, con la promoción cada vez mayor de los Métodos Alternativos de Solución de Conflictos, conocidos como MASC.

Segunda: La mediación y la conciliación cobran más cabida en los asuntos que atañen a la familia en general, en los cuales se trata de proteger a los menores de edad, puesto que éstos han dejado de ser objetos de derecho, para convertirse en sujetos del mismo y es posible llevar a cabo esta importante tarea con el apoyo conjunto de las instituciones también, cuyo papel debe ser palpable; en la actualidad, se parte del nuevo paradigma de los derechos humanos, resolviendo los órganos jurisdiccionales con justicia pronta y expedita, completa e imparcial, pero sobre todo con igualdad, sin discriminación y con una perspectiva de equidad de género e incluso con interculturalidad.

Tercera: El desjudicializar la familia, como algunos autores contemporáneos pretenden, sería una decisión extrema que fracasaría, ya que es de gran relevancia esta institución, porque independientemente de la denominación que se le dé, es un grupo primario fundamental de convivencia dentro de la sociedad; no siendo posible que administrativamente o notarialmente se resuelvan los conflictos de sus miembros. A pesar de la modernidad, debe seguir siendo una responsabilidad compartida, de Estado, Gobierno y de las propias cabezas de familia regularlo y que sus controversias sean resueltos en sede judicial, pero a través de procedimientos más ágiles y transparentes como los juicios orales.

Cuarta: El actuar de las instituciones cobra vital importancia cuando se trata de la familia, porque se debe realizar un trabajo conjunto, para que de manera integral se obtengan resultados que repercutan en el bienestar de los menores de edad; siendo esto una tarea de todos los ámbitos de gobierno, federal, estatal, municipal y la propia Ciudad de México el contribuir para que se dé una asesoría jurídica gratuita y de acompañamiento a los miembros de la familia.

Quinta: En algunos Estados de la República Mexicana, como Guanajuato, existe Representación Gratuita en Materia Civil, dependiente de la Secretaría de Gobierno, así que el Poder Ejecutivo Estatal es quien cubre los salarios de estos licenciados en derecho que fungen como mandatarios judiciales de personas de escasos recursos económicos y que actualmente desempeñan su función en la mayoría de los municipios de la Entidad; aun cuando en algunos sólo hay un par de abogados de dicha representación gratuita y son insuficientes, lo ideal sería que se dedicaran específicamente a llevar asuntos de la materia familiar, porque en este sector las personas carecen de recursos y tienen mayores problemas que necesitan resolver mediante intervención judicial.

Sexta: La jurisprudencia actual, como fuente formal del Derecho, ha venido interpretando la ley, porque ésta no se ha venido actualizando como debería, ya que la sociedad cambia con mayor rapidez y supera las normas; el nuevo paradigma constitucional de los derechos humanos, cobra aplicación y los principios como el llamado interés superior del menor, son premisas que están revolucionando los procesos judiciales, como los juicios sobre la familia en donde principios como la oficiosidad y suplencia imperan. 


\section{FUENTES}

BIBLIOGRÁFICAS

BAQUEIRO ROJAS, Édgard y BUENROSTRO BÁEZ, Rosalía, Derecho de familia, 2ª ed., edit. Oxford, México, 2009.

COUTURE, Eduardo J., Vocabulario Jurídico, con Especial Referencia al Derecho Procesal Vigente Uruguayo, edit. Depalma, Argentina 1988.

DE LA MATA PIZAÑA, Felipe y GARZÓN JIMÉNEZ, Roberto, Derecho Familiar, $4^{\mathrm{a}}$ ed., edit. Porrúa, México, 2008.

GARCÍA RAMÍREZ, Sergio, Derechos Humanos para los Menores de Edad. Perspectiva de la Jurisdicción Interamericana, $1^{\text {a }}$ ed., edit. UNAM, México, 2010.

GORJÓN GÓMEZ, Francisco J. y STEELE GARZA, José G., Métodos alternativos de solución de conflictos, edit. Oxford, México, 2008.

GUTIÉRREZ Y GONZÁLEZ Ernesto, Derecho Civil para la Familia, 2ª ed., edit. Porrúa, México, 2009.

HUBER OLEA, Francisco José, Diccionario de Derecho Romano comparado con Derecho Mexicano, edit. Porrúa, México, 2000.

REVISTAS JURÍDICAS

AGUILAR CAMACHO, Mario Jesús, "Política y Derecho. Estudios para la Construcción de la Diversidad Democrática", en Enciclopedia y Biblioteca Virtual de las Ciencias Sociales, Económica y Jurídicas, 2011, http://www.eumed/. 26 de agosto 2015.

ÁLVAREZ TORRES, Osvaldo M. “¿Por qué la desjudicialización de la justicia de familia?”, en Contribuciones a las Ciencias Sociales, marzo 2011, www.eumed.net/.20 de agosto de 2015 .

BENAVIDES SANTOS, Diego. “Tendencias del Proceso Familiar en América Latina”, en Revista INDRET para el Análisis del Derecho, 2006, año 1, número 321, Barcelona España, http://www.indret.com.18 de agosto de 2015.

COUTIÑO, Castro Matilde, "El Derecho de los Menores: Una Perspectiva Nacional e Internacional”, en Biblioteca Jurídica Virtual del Instituto de Investigaciones Jurídicas de la UNAM, en http://www.juridicas.unam.mx/.13 de julio de 2015.

CHÁVEZ PADRÓN, Martha, “El Proceso de Integración Jurisprudencial en el Sistema Jurídico Mexicano”, en Biblioteca Jurídica Virtual del Instituto de Investigaciones Jurídicas de la UNAM, http://www.juridicas.unam.mx.12 de agosto 2015.

GUITRÓN FUENTEVILLA, Julían, “Derecho Familiar”, en Revista Jurídica UNAM, 1978, México, en http://www.juridicas.unam.mx. 2 de agosto 2015. 
JIMÉNEZ GARCÍA, Joel Francisco, “Derecho de los Niños”, en Instituto de Investigaciones Jurídicas de la UNAM, México, 2000.

PÉREZ CONTRERAS, María Montserrat, "Comentarios a la Ley para la Protección de los Derechos de Niñas, Niños y Adolescentes”, en Revista de la Facultad de Derecho de la Universidad Autónoma de México, número 235, tomo LI, México, 2001.

PÉREZ MANRIQUE, Ricardo C., "Participación Judicial de los Niños, Niñas y Adolescentes”, en Revista Justicia y Derechos del Niño, Número 8, Sección Primera, Artículos para el Debate, $1^{\mathrm{a}}$ ed., Santiago de Chile, UNICEF, pp. 219-248 2006, http://www. unicef.org/argentina/spanish/JusticiayDerechos.17 de agosto de 2015.

LEGISLACIÓN

Constitución Política de los Estados Unidos Mexicanos, 2015.

Ley de Relaciones Familiares de 1917.

Código Civil para el Estado de Guanajuato, 2015.

Código de Procedimientos Civiles para el Estado de Guanajuato, 2015.

Compilación de Tratados Internacionales sobre Protección de la Persona aplicables en México, Derecho Internacional de los Derechos Humanos, en http://www.scjn.gob.mx/ libro/documents/instrumentosinternacionales.pdf.30 de julio 2015.

INTERNET

Diario Oficial de la Federación, en: http://www.dof.gob.mx/

Instituto Nacional de las Mujeres (Inmujeres), en: http://www.inmujeres.gob.mx/

Organización de las Naciones Unidas (ONU), en: http://www.un.org/es/index.html

Poder Judicial del Estado de Guanajuato, en http://www.poderjudicial-gto.gob.mx/

Semanario Judicial de la Federación, en http://sjf.scjn.gob.mx/

Suprema Corte de Justicia de la Nación, en http://www.diputados.gob.mx/

TABLA DE SIGLAS

CPEUM Constitución Política de los Estados Unidos Mexicanos

DIF Desarrollo Integral de la Familia

DOF Diario Oficial de la Federación

MASC Métodos Alternativos de Solución de Conflictos 
MP Ministerio Público

PO Periódico Oficial

SCJN Suprema Corte de Justicia de la Nación

SOF Sistema Oral Familiar

UNAM Universidad Nacional Autónoma de México 